\title{
Boron sulfonic acid (BSA) catalyzed selective synthesis of aryl-bis(2- hydroxynaphth-1-yl)methanes and 14-alkyl- and 14-aryl-14H-dibenzoxanthenes under solvent-free condition
}

\author{
P. Dutta and R. Borah*
}

Department of Chemical Sciences, Tezpur University, Napaam-784028, Tezpur-Assam, India

\begin{tabular}{l}
\hline C H R O N I C L E \\
\hline Article history: \\
Received January 21, 2015 \\
Received in revised form \\
March 29, 2015 \\
Accepted 9 April 2015 \\
Available online \\
9 April 2015 \\
\hline Keywords: \\
Aryl-bis(2-hydroxy-1- \\
naphthyl)methanes \\
Dibenzoxanthenes \\
B(HSO4)3 \\
Reusable solid acid \\
Neat condition \\
\hline
\end{tabular}
A B S T R A C T

This study investigated the selective synthesis of aryl-bis(2-hydroxy-1-naphthyl)methane for the first time under microwave irradiation in solvent-free medium within 5 min using $10 \mathrm{~mol}$ $\%$ of $\mathrm{B}\left(\mathrm{HSO}_{4}\right)_{3}(\mathrm{BSA})$ as reusable solid acid catalyst. The same reaction could also be conducted at $90-100{ }^{\circ} \mathrm{C}$ in neat for the formation of alkyl or aryl $14 \mathrm{H}$-dibenzoxanthenes in presence of BSA catalyst with excellent yields.

Neat condition

\section{Introduction}

The efficient applications of solid acid catalyst in organic synthesis have encouraged the chemists to devise new reagents and methods that are innocuous to the environment. ${ }^{1}$ Most of these solid acids are safe, non-corrosive, easy separation via filtration, recyclable, cheaper, chemo selective and product selective in various reaction conditions. ${ }^{2}$ Boron sulfonic acid (BSA) is a versatile solid acid which was first introduced by Kiasat et al that makes reaction processes convenient, more economic, and environmentally benign (Scheme 1 ). ${ }^{3}$ Owing to the numerous advantages associated with this cheap and non-hazardous reagent, BSA has been explored as a powerful catalyst for various organic transformations under mild conditions. ${ }^{4}$ In continuation of our research work on solid acid catalysed organic transformations, ${ }^{5-6}$ we have the opportunity to explore the catalytic activity of BSA for the selective generation of 14-alkyl or aryl $14 \mathrm{H}$-dibenzoxanthenes and its precursors aryl or alkyl-bis(2hydroxy-1-naphthyl)methane from the acid catalysed reaction of 2-naphthol with aldehydes (Scheme * Corresponding author.

E-mail address: ruli@tezu.ernet.in (R. Borah) 
2). Both dibenzoxanthene $\underline{4}$ and bisnaphthol $\underline{3}$ derivatives have wide range of applications in medicinal chemistry as antiviral, antibacterial, and anti-inflammatory activities, anticancer, and anti-analgesic activity ${ }^{7-8}$ In material science, dibenzoxanthene can be used as dyes, in laser technology, $\mathrm{pH}$-sensitive fluorescent materials for the visualization of biomolecular assemblies ${ }^{9-10}$ and in photodynamic therapy. ${ }^{11-12}$ Similarly bisnaphthol derivatives are applicable as non-linear optical materials, ionselective electrodes or sensors, chiral ligands in organometallic chemistry, synthetic precursors for the formation of spirans and sometimes, as high-performance liquid chromatography stationary phases with some modifications. ${ }^{13-14}$

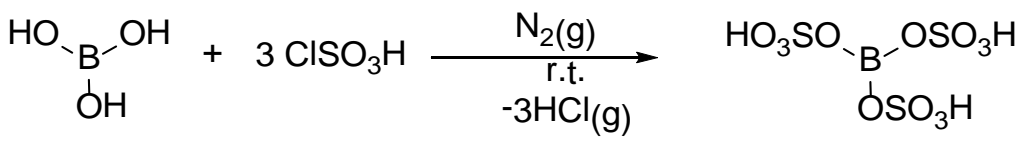

Scheme 1. Preparation of boron sulfonic acid catalyst.

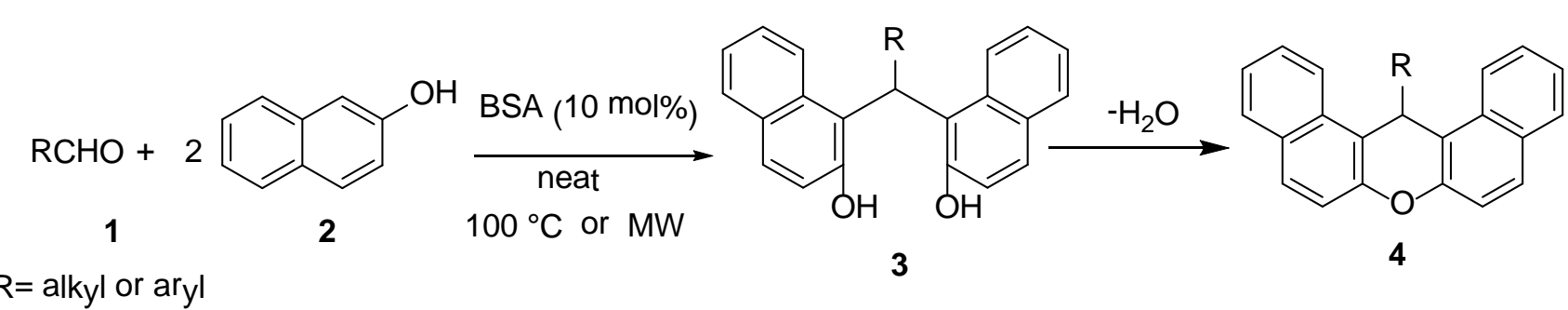

Scheme 2. Synthesis of bisnaphthol (יㅜ) and dibenzoxanthene (י) derivatives.

A large number of acid catalysts have been reported in literature for the synthesis of dibenzoxanthenes which include traditional Brönsted/Lewis acids along with reusable heterogeneous acids. ${ }^{15}$ Some of the examples of solid acids are Amberlyst- $15,{ }^{2}$ silica sulfuric acid, ${ }^{16} \mathrm{HClO}_{4} / \mathrm{SiO}_{2},{ }^{17}$ heteropoly acid, ${ }^{18} \mathrm{Yb}(\mathrm{OTf}) 3,{ }^{19}$ montmorillonite $\mathrm{K}-10^{20}$ and cellulose sulfuric acid. ${ }^{21}$ Most of the acid catalysed synthesis of dibenzoxanthene (Scheme 2) described the selective formation of required product without the intermediary of aryl or alkyl di-(2-hydroxy-1-naphthyl)methanes under solventfree thermal treatment or in microwave irradiation. The literature survey shows few reports on the synthesis of aryl or alkyl di-(2-hydroxy-1-naphthyl) methane from aldehydes and 2-naphthol. ${ }^{22-24}$ The preparations of bisnaphthols were described as lower yields from the mixture of 2-naphthol and benzaldehyde in $\mathrm{AcOH}$ using conc. $\mathrm{HCl}$ for $50 \mathrm{~h}$ in refrigerator. ${ }^{22}$ Alizadeh et al introduced $\mathrm{H}_{3}\left[\mathrm{P}\left(\mathrm{Mo}_{3} \mathrm{O}_{10}\right)_{4}\right] \cdot \mathrm{nH}_{2} \mathrm{O}$ as reusable heteropolyacids catalyst in refluxing dichloromethane. ${ }^{23}$ Similarly the condensation of phenols with aromatic aldehydes in ethanol utilized 3 kbar pressure in 24 hours at $60{ }^{\circ} \mathrm{C}$ in presence of TfOH catalyst to produce good to excellent yields of bisnaphthols. ${ }^{24}$ All these studies reveal that there is a scope to study the selective synthesis of both compounds ( $\underline{\mathbf{3}} \& \underline{\mathbf{4}})$ in presence of reactive BSA as reusable solid catalyst under thermal and microwave energies with the incorporation of more number of greener components. It is well established that the combination of microwave energy with solvent-free medium reduces the reaction time and thus make the reaction path cleaner by single product formation. ${ }^{25}$ By considering the multifaceted advantages of microwave assisted organic synthesis we decided to investigate the BSA catalyzed reaction of 2-naphthol and aldehydes under microwave irradiation and compare the results with thermal energy to identify the exact conditions for selective synthesis of $\underline{\mathbf{3}}$ and $\underline{\mathbf{4}}$.

\section{Results and Discussion}

Initially, we optimized the amount of BSA catalyst with the model reaction of benzaldehyde (1 mmol) and 2-naphthol (2 mmol) (Table 1) in solvent-free medium under thermal as well as microwave energies to study the appropriate conditions for the selective synthesis of aryl-bis (2-hydroxy-1naphthyl) methane $\underline{\mathbf{3 a}}$ and dibenzoxanthene derivatives $\underline{\mathbf{4 a}}$. All the reactions were monitored by thin layer chromatography using 1: 5 ethyl acetate and hexane as solvent system. 
Table 1. Standardization of the amount of catalyst using BSA catalyst

\begin{tabular}{ccccccc} 
Entry & $\begin{array}{c}\text { BSA } \\
\text { (mol \%) }\end{array}$ & \multicolumn{2}{c}{$\begin{array}{c}\text { Time }^{\mathbf{a}} \\
\text { (min) }\end{array}$} & $\begin{array}{c}\text { MW Power } \\
\text { Method B } \\
\text { (W) }\end{array}$ & \multicolumn{2}{c}{$\begin{array}{c}\text { Product } \\
\text { Yields (\%) }\end{array}$} \\
\hline 1 & & A & B & & $\underline{\mathbf{3}}$ (A/B) & $\underline{\mathbf{4}}$ (A/B) \\
\hline 2 & 5 & 60 & 5 & 500 & $10 / 10$ & $50 / 10$ \\
3 & 15 & 5 & 500 & $10 / 25$ & $68 / 10$ \\
4 & 10 & 15 & 5 & 500 & $-/ 80$ & $96 / 15$ \\
5 & 10 & - & 5 & 625 & $-/-$ & $-/ 95$ \\
\hline
\end{tabular}

${ }^{\text {a }}$ Methods A: solvent-free thermal method at $100^{\circ} \mathrm{C}$; B: microwave irradiation in neat condition

These studies clearly identified two optimized conditions for selective formation of $\underline{\mathbf{3 a}}$ and $\underline{\mathbf{4 a}}$ under microwave and thermal energies with $10 \mathrm{~mol} \%$ of BSA catalyst (Table 1, entry 3). The thermal treatment needed $100{ }^{\circ} \mathrm{C}$ to give $96 \%$ yield of dibenzoxanthene 4 a during 15 min reaction time (Table 1 , entry 3) whereas it was $80 \%$ yield of bisnaphthol 3a within 5 min with $500 \mathrm{~W}$ microwave power irradiation (Table 1, entry 3). The reaction mixture was found with unreacted 2-naphthol at $80{ }^{\circ} \mathrm{C}$ in neat condition. It was observed that at $500 \mathrm{~W}$ microwave power, the reaction produced only $15 \%$ of dibenzoxanthene $\underline{\mathbf{4 a}}$ and major amount of bisnaphthol $\underline{\mathbf{3 a}}$ in the presence of $10 \mathrm{~mol} \%$ of BSA catalyst (Table 1, entry 3). Interestingly, the conversion of bisnaphthol 3a to dibenzoxanthene $\underline{\mathbf{4 a}}$ became faster upon increasing the MW power to $25 \%$ with $10 \mathrm{~mol} \%$ of BSA for 5 min irradiation (Table 1, entry 4). The use of $25 \mathrm{~mol} \%$ of BSA produced dibenzoxanthene $\mathbf{4 a}$ as sole product in both methods within 10 min at $100{ }^{\circ} \mathrm{C}$ in thermal treatment and at $50 \%$ lower microwave power than the power of bisnaphthol 3a synthesis under optimized condition (Table 1, entry 5).This observation showed the product selectivity of BSA catalyst against its variations of amounts under thermal and microwave conditions. From this study, we selected $10 \mathrm{~mol} \%$ and $25 \mathrm{~mol} \%$ of BSA as the optimized amounts for the selective formation of bisnaphthol $\underline{\mathbf{3 a}}$ and dibenzoxanthene derivatives $\underline{\mathbf{4 a}}$ in thermal method at $100{ }^{\circ} \mathrm{C}$ and different microwave energies in solvent-free conditions. The model reaction was not efficient to produce good yields of products in water, dichloromethane, chloroform and ethanol under reflux in solution as compared to neat environment. The results were unacceptable both in terms of yield of the product and time for the completion of the reaction as compared to the solvent-free system.

1<smiles>[R]C=CCOCCOS(=O)(=O)O</smiles><smiles>[R]C(c1c(O)ccc2ccccc12)c1c(O)ccc2ccccc12</smiles>

3<smiles>C1C[AsH2]C1</smiles>

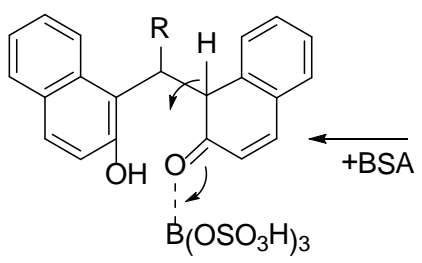

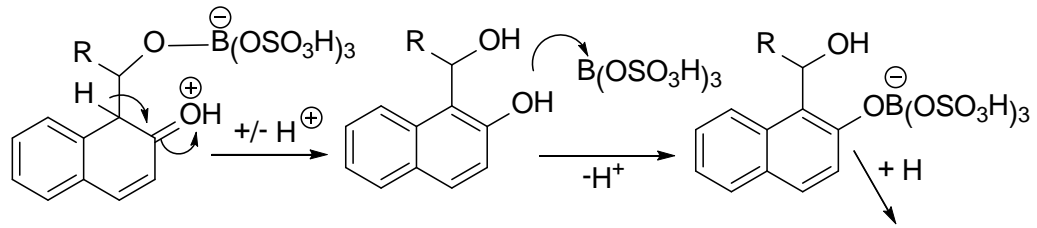<smiles>[R]C1c2c(ccc3ccccc23)Oc2ccc3oc4ccccc4c3c21</smiles><smiles>[R]C(O)CO</smiles>

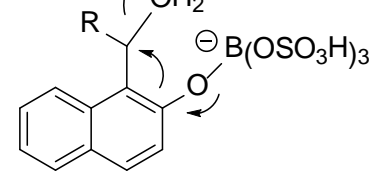

$\mathrm{H}$ 1 $-\mathrm{H}_{2} \mathrm{O}$ -BSA

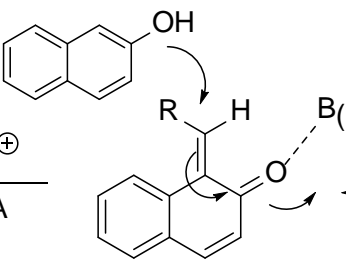<smiles>[SeH2]O[SeH2]O[SeH2]</smiles><smiles>[SbH3]</smiles><smiles>[R]/C=C1/C(=O)C=Cc2ccccc21</smiles> 
By considering the above optimization studies, we extended the synthesis of alkyl or aryl-bis (2hydroxy-1-naphthyl) methane $\underline{\mathbf{3}}$ and their dehydration product dibenzoxanthene $\underline{\mathbf{4}}$ with different aldehydes in solvent-free medium using both energy sources with $10 \mathrm{~mol} \%$ and $25 \mathrm{~mol} \%$ of BSA catalysts. All these observations were included in Table 2. The plausible mechanism of BSA catalyzed synthesis of dibenzoxanthene $\underline{\mathbf{4 a}}$ and bisnaphthol $\underline{3 \mathbf{a}}$ can be expressed according to Scheme $3 .{ }^{29,30}$

The results in Table 2 showed selective behaviour of BSA catalyst for the formation of dibenzoxanthene $\underline{4}$ at $100^{\circ} \mathrm{C}$ with $10 \mathrm{~mol} \%$ of catalyst from aliphatic or aromatic aldehydes except 4nitrobenzaldehyde (Table 2, entry 2).The same amount of catalyst generated bisnaphthol $\underline{\mathbf{3}}$ as major product from aromatic aldehydes (75-96 \%) under microwave in short time excluding $p$-tolualdehyde (Table 2, entry 5).

Table 2. Formation of $\underline{\mathbf{3}}$ and $\underline{4}$ with different aldehydes using BSA catalyst in solvent-free methods

\begin{tabular}{|c|c|c|c|c|c|c|}
\hline Entry & $\begin{array}{c}\text { Aldehyde, } \\
\text { R- }\end{array}$ & $\begin{array}{c}\text { MW Power } \\
\text { (W) } \\
\text { (Method B) }\end{array}$ & $\begin{array}{c}\text { BSA } \\
(\mathrm{mol} \%)\end{array}$ & $\begin{array}{c}\text { Time } \\
(\min ) \\
(\operatorname{Method} A / B)^{a}\end{array}$ & $\begin{array}{c}\text { Yield (\%) } \\
\underline{\mathbf{3}}^{24,27} \\
\text { (Method A/B) }\end{array}$ & $\begin{array}{c}\text { Yield (\%) } \\
\underline{\mathbf{4}}^{17,26,27,28} \\
\text { (Method A/B ) }\end{array}$ \\
\hline 1 & $\frac{1 \mathrm{a}}{\mathrm{Ph}}$ & $\begin{array}{l}500 \\
625 \\
250\end{array}$ & $\begin{array}{l}10 \\
10 \\
25\end{array}$ & $\begin{array}{c}15(\mathrm{~A}) / 5(\mathrm{~B}) \\
5(\mathrm{~B}) \\
10(\mathrm{~A}) / 5(\mathrm{~B})\end{array}$ & $\begin{array}{c}-/ 80(\mathrm{~B}) \\
- \\
-\end{array}$ & $\begin{array}{c}96(\mathrm{~A}) / 5(\mathrm{~B}) \\
87(\mathrm{~B}) \\
97(\mathrm{~A}) / 92(\mathrm{~B})\end{array}$ \\
\hline 2 & $\frac{\underline{\mathbf{1 b}}}{4-\mathrm{NO}_{2}} \mathrm{C}_{6} \mathrm{H}_{4}$ & $\begin{array}{l}625 \\
625\end{array}$ & $\begin{array}{l}10 \\
25\end{array}$ & $\begin{array}{l}15(\mathrm{~A}) / 3(\mathrm{~B}) \\
60(\mathrm{~A}) / 5(\mathrm{~B})\end{array}$ & $\begin{array}{l}95(\mathrm{~A}) / 96(\mathrm{~B}) \\
72(\mathrm{~A}) / 75(\mathrm{~B})\end{array}$ & $24(\mathrm{~A}) / 15(\mathrm{~B})$ \\
\hline 3 & $\frac{\text { 1c }}{4-\mathrm{CH}_{3} \mathrm{OC}_{6} \mathrm{H}_{4}}$ & $\begin{array}{l}250 \\
500\end{array}$ & $\begin{array}{l}10 \\
25\end{array}$ & $\begin{array}{c}45(\mathrm{~A}) / 5(\mathrm{~B}) \\
5(\mathrm{~B})\end{array}$ & $\begin{array}{c}-/ 75(\mathrm{~B}) \\
65(\mathrm{~B})\end{array}$ & $\begin{array}{c}70(\mathrm{~A}) /- \\
25(\mathrm{~B})\end{array}$ \\
\hline 4 & ${ }_{4-\mathrm{ClC}_{6}} \mathrm{H}_{4}$ & $\begin{array}{l}625 \\
750\end{array}$ & $\begin{array}{l}10 \\
25\end{array}$ & $\begin{array}{c}15(\mathrm{~A}) / 3(\mathrm{~B}) \\
3(\mathrm{~B})\end{array}$ & $\begin{array}{c}-/ 92(\mathrm{~B}) \\
70(\mathrm{~B})\end{array}$ & $\begin{array}{c}\text { 90(A)/- } \\
22(\mathrm{~B})\end{array}$ \\
\hline 5 & $\frac{1 \mathbf{e}}{4-\mathrm{CH}_{3}} \mathrm{C}_{6} \mathrm{H}_{4}$ & $\begin{array}{l}375 \\
625\end{array}$ & $\begin{array}{l}10 \\
25\end{array}$ & $\begin{array}{c}30(\mathrm{~A}) / 5(\mathrm{~B}) \\
2(\mathrm{~B})\end{array}$ & - & $\begin{array}{c}80(\mathrm{~A}) / 85(\mathrm{~B}) \\
96(\mathrm{~B})\end{array}$ \\
\hline 6 & $\left.\mathrm{CH}_{3} \stackrel{\underline{\mathbf{1 f}}}{(\mathrm{C}} \mathrm{H}_{2}\right)_{2}$ & 250 & 10 & $40(\mathrm{~A}) / 5(\mathrm{~B})$ & - & $75(\mathrm{~A}) / 10(\mathrm{~B})$ \\
\hline 7 & $\stackrel{1 \mathbf{g}}{\text { fur-2-yl }}$ & 500 & 10 & 15(A)/5(B) & $\begin{array}{c}\text { Polymeric } \\
\text { products }\end{array}$ & - \\
\hline 8 & $\frac{\mathbf{1 h}}{\text { naphth-2-yl }}$ & $\begin{array}{l}500 \\
625\end{array}$ & $\begin{array}{l}10 \\
25\end{array}$ & $\begin{array}{l}40(\mathrm{~A}) / 5(\mathrm{~B}) \\
60(\mathrm{~A}) / 3(\mathrm{~B})\end{array}$ & $\begin{array}{c}30(\mathrm{~A}) / 85(\mathrm{~B}) \\
-/ 60(\mathrm{~B})\end{array}$ & $\begin{array}{c}65(\mathrm{~A}) /- \\
85(\mathrm{~A}) / 30(\mathrm{~B})\end{array}$ \\
\hline 9 & $\mathrm{PhCH}=\mathrm{\mathbf {1i }}=\mathrm{CH}$ & 250 & 10 & $15(\mathrm{~A}) / 5(\mathrm{~B})$ & 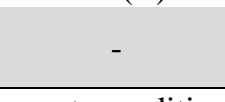 & $95(\mathrm{~A}) / 90(\mathrm{~B})$ \\
\hline
\end{tabular}

${ }^{\mathrm{a}}$ Methods A: solvent-free thermal method at $100^{\circ} \mathrm{C}$; B : microwave irradiation in neat condition ; ${ }^{\mathrm{b}}$ Isolated products; ${ }^{\mathrm{c}}$ All the isolated products are known and characterized by comparing their melting point, ${ }^{1} \mathrm{H}$ NMR, ${ }^{13} \mathrm{C}$ NMR and elemental analysis data with reported literature. ${ }^{24,17,26-28}$

Cinnamaldehyde produced dibenzoxanthene $\underline{\mathbf{4}} \mathbf{i}$ as single product under microwave and thermal energies (Table 2, entry 9). Butanal formed dibenzoxanthene as major product in thermal method at $90^{\circ} \mathrm{C}$ with $10 \mathrm{~mol} \%$ of BSA (Table 2, entry 6). The BSA catalyst lost its selectivity with $25 \mathrm{~mol} \%$ under microwave irradiation for the formation of bisnaphthol derivatives while benzaldehyde and $p$ tolualdehyde yielded dibenzoxanthene as major product (Table 2, entries 1, 5).

The recyclability of the catalyst was tested by conducting the model reaction of benzaldehyde and 2-naphthol with $10 \mathrm{~mol} \%$ of BSA at $100{ }^{\circ} \mathrm{C}$ for the preparation of dibenzoxanthene $\underline{3 a}$ for four cycles. The results obtained were depicted in Fig. 1. 


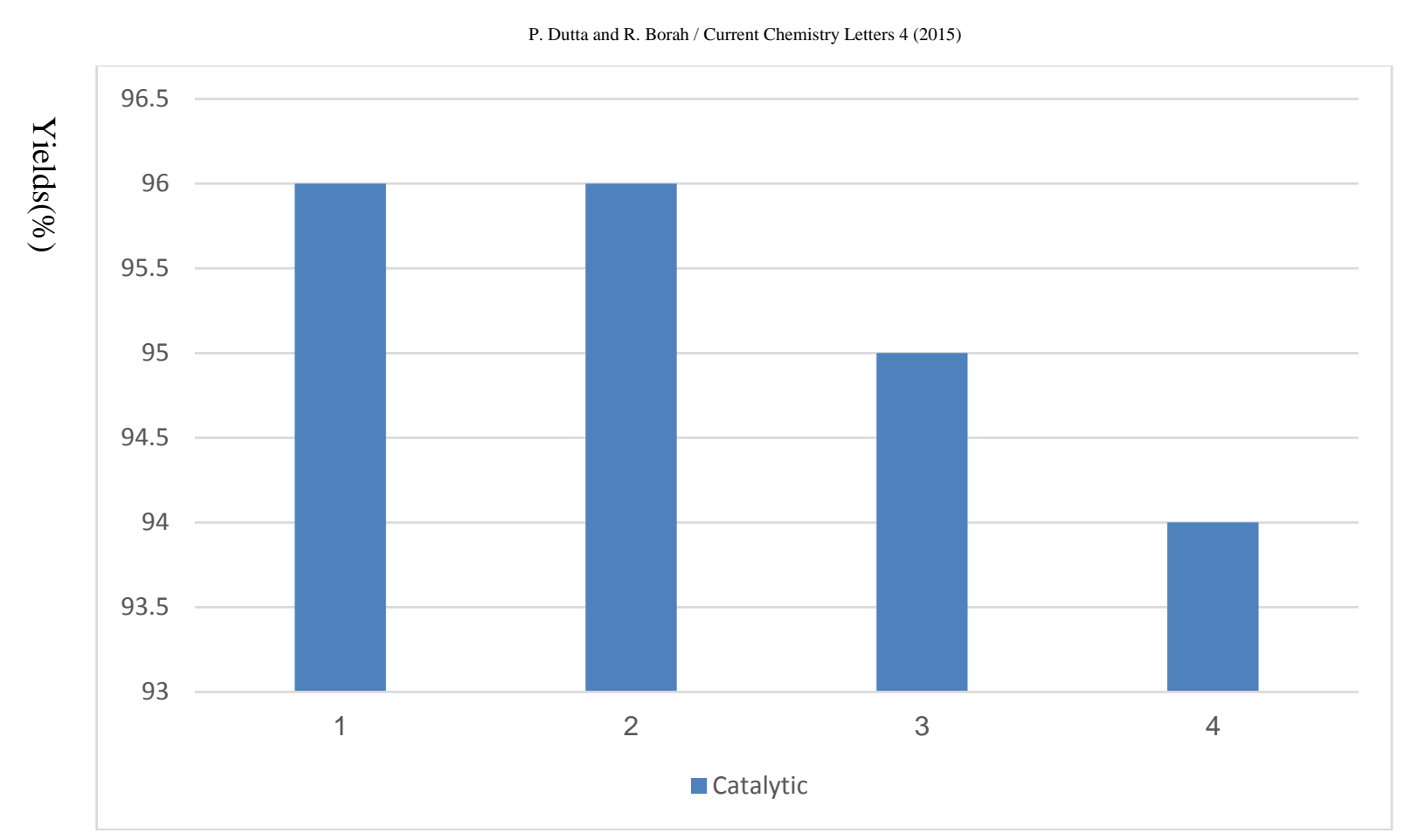

Fig. 1. Recycling of BSA catalyst for the preparation of $\underline{\mathbf{3 a}}$ at $100{ }^{\circ} \mathrm{C}$.

\section{Conclusions}

This study explored the catalytic activities of boron sulfonic acid as reusable solid acid in neat conditions for the selective preparation of dibenzoxanthene and its precursor intermediate bisnaphthol under thermal and microwave energies in an efficient way. We observed different selectivity of BSA catalyst towards the synthesis of dibenzoxanthene in thermal and microwave conditions with variation of the amount of catalysts under optimized conditions. The catalyst was found to be recyclable for four runs for the synthesis of dibenzoxanthene and thus making it quite attractive in terms of green chemistry. Moreover, this is the first method for the selective synthesis of aryl-bis (2-hydroxy-1naphthyl)methane under microwave irradiation in presence of a heterogeneous catalyst with excellent yields of product. In both conditions the selective syntheses of bisnaphthol and dibenzoxanthene derivatives were possible within 5-60 min reaction time.

\section{Acknowledgements}

The authors are thankful to Sophisticated Intrument Facility and Department of Chemical Sciences, Tezpur University for analysis of various samples for this work. The co-author of the paper expresses her acknowledgement to University Grants Commission, New Delhi for financial assistance under BSR scheme.

\section{Experimental}

\subsection{Materials and Methods}

All chemicals were purchased from chemical supplier and were used without purification. ${ }^{1} \mathrm{H}$ and ${ }^{13} \mathrm{C}$ NMR spectra were recorded on a JEOL JNM ECS- 400 MHz FT-NMR spectrometer in $\mathrm{CDCl}_{3}$ solution using TMS as internal standard. $J$-values were given in Hertz. IR spectra were recorded on a Nicolet Impact-410 spectrometer. The products were identified by comparison of their FT-IR, ${ }^{1} \mathrm{H}$ and ${ }^{13} \mathrm{C}$ NMR 
spectroscopic data with those of authentic compounds and literature reported data. ${ }^{17,24,26-28}$ The elemental analysis were performed on Perkin Elmer 20-analyzer. Melting points were recorded in a Buchi B-540 melting point apparatus and were uncorrected.

\subsection{Preparation of Boron Sulfonic Acid (BSA)}

The boron sulfonic acid (BSA) catalyst was prepared via the reaction of boric acid with chlorosulfonic acid by following the procedure reported by Kiasat et al in $2008 .^{3}$ A $50 \mathrm{~mL}$ suction flask fitted with a constant pressure dropping funnel was connected to a vacuum system through water and an alkali trap. To the flak, $12 \mathrm{mmol}$ of boric acid was introduced and after that, $36 \mathrm{mmol}$ of chlorosulfonic acid was added drop wise over a period of an hour at ambient temperature with the help of pressure dropping funnel. The immediately evolved $\mathrm{HCl}$ generated was trapped by the water and alkali solutions through suction. Once the addition was completed, the resulting mixture was shaken for an hour. The solid residue was washed with diethyl ether to remove the unreacted chlorosulfonic acid. Finally, the product was collected as grey solid with $94 \%$ yield.

\subsection{Typical Procedure for the Preparation of 14-Alkyl or Aryl-14H-Dibenzoxanthenes 4 under Solvent-} free Thermal Energy

A mixture of aldehyde $(1 \mathrm{mmol})$ and $\beta$-naphthol $(2 \mathrm{mmol})$ along with BSA ( $10 \mathrm{~mol} \%)$ was grounded in mortar into a fine powder and was introduced in a $50 \mathrm{ml}$ round bottomed flask fitted with a reflux condenser to a preheated oil bath at $100^{\circ} \mathrm{C}$ for the specified time. After completion of the reaction as indicated by TLC, the mixture was diluted with ethyl acetate $(5 \mathrm{ml})$ and filtered to isolate the solid catalyst for recycling. The crude filtrate was washed with dilute aqueous sodium hydroxide solution to remove the unreacted 2-naphthol. The organic extract was dried over anhydrous $\mathrm{Na}_{2} \mathrm{SO}_{4}$ and distilled under reduced pressure to furnish the crude product. The crude product was further purified by preparative TLC (thin layer chromatography) with ethyl acetate and hexane as solvent system to isolate the analytically pure product.

4.4 Typical Procedure for the Preparation of Aryl-bis (2-hydroxy-1-naphthyl)methanes $\underline{3}$ and 14-Alkyl or aryl -14H-dibenzoxanthenes $\underline{4}$ under microwave energy

A mixture of finely grounded aldehyde (1 mmol) , 2-naphthol $(2 \mathrm{mmol})$ and BSA( $10 \mathrm{~mol} \%$ or 25 mol\%) was irradiated at different power level in a microwave reactor (Catalyst System) for the specified time as mentioned in the table 2. After completion of the reaction, as indicated by TLC, the reaction mixture was cooled to room temperature and ethyl acetate was added in order to recover the insoluble catalyst by filtration. The filtrate was washed with dilute aqueous sodium hydroxide solution to remove the unreacted 2-naphthol. The organic extract was dried over anhydrous $\mathrm{Na}_{2} \mathrm{SO}_{4}$ and distilled under reduced pressure to furnish the crude product. The crude product was purified by preparative chromatography using ethyl acetate and hexane as solvent system to get analytically pure product.

\subsection{Selected Spectral Data of Aryl-bis (2-hydroxy-1-naphthyl)Methanes $\underline{\mathbf{3}}$ and Dibenzoxanthene Derivatives $\underline{4}$ :}

4.5.1. Phenyl-bis(2-hydroxy-1-naphthyl) methane (3a) (table 2, entry 1). M.p. 203-205 ${ }^{\circ} \mathrm{C}$. IR: 3422, 2926, 2378, 1953, 1618, 1505, 1436, 1358, 1257, 1210, 1146, 1031, 957, 813, 749, $699 \mathrm{~cm}^{-1} .{ }^{1} \mathrm{H}$ NMR: $6.3(\mathrm{~s}, 1 \mathrm{H}), 7.01$ (d, $J=8.7 \mathrm{~Hz}, 2 \mathrm{H}), 7.20-7.39(\mathrm{~m}, 9 \mathrm{H}), 7.7$ (d, $J=9.1 \mathrm{~Hz}, 2 \mathrm{H}), 7.8$ (d, $J=8.2 \mathrm{~Hz}, 2 \mathrm{H})$, 7.91 (d, $J=8.2 \mathrm{~Hz}, 2 \mathrm{H}) .{ }^{13} \mathrm{C}$ NMR: 42.7, 118.6, 119.9, 122.6, 123.6, 127.5, 128.4, 129, 129.7, 129.9, 130.1, 133.6, 140.6, 152.9. CHN analysis: Calcd. for $\mathrm{C}_{27} \mathrm{H}_{20} \mathrm{O}_{2}$ (\%): C 86.17, H 5.31, Found: C 86.21, H 5.35.

4.5.2. 14-(4-Methylphenyl)-14H-dibenzo[a,j]xanthenes $4 \boldsymbol{e}$ (table 2, entry 5). M.p. $229.1^{\circ} \mathrm{C}$. IR: 3068, 2917, 1626, 1597, 1515, 1466, 1437, 1404, 1258, 1125, 1087, 967, 840, 815, 785, $745 \mathrm{~cm}^{-1} .{ }^{1} \mathrm{H}$ NMR: 2.3 (s, 3H), 6.14 (s, 1H), 6.77 (d, $J=7.8 \mathrm{~Hz}, 2 \mathrm{H}), 6.91(\mathrm{t}, J=7.3 \mathrm{~Hz}, 1 \mathrm{H}), 7.13-7.16(\mathrm{~m}, 6 \mathrm{H}), 7.27$ (t, $J=6.9 \mathrm{~Hz}, 1 \mathrm{H}), 7.36$ (d, $J=7.8 \mathrm{~Hz}, 3 \mathrm{H}), 7.69-7.78$ (m, 3H). ${ }^{13} \mathrm{C}$ NMR: 21.1, 62.7, 111.8, 116.5, 121.4, 
122.8, 126.8, 127.9, 128.9, 129.1, 129.4, 129.9, 130, 138.4, 146.5, 156, 199.9. CHN analysis: Calcd. for $\mathrm{C}_{28} \mathrm{H}_{20} \mathrm{O}$ (\%): C 90.32, H 5.37, Found C 90.37, H 5.40.

\section{References}

1. Clark J. H. (2002) Solid acids for green chemistry. Acc. Chem. Res., 35(9), 791-797.

2. Ko S., Yao C.-F. (2006) Heterogeneous catalyst: Amberlyst-15 catalyzes the synthesis of14substituted-14H-dibenzo[a,j]xanthenes under solvent-free conditions. Tetra. Lett, 47 (50), 88278829.

3. Kiasat A. R., Fallah-Mehrjardi M. (2008) B(HSO 4$)_{3}$ : A novel and efficient solid acid catalyst for the regioselective conversion of epoxides to thiocyanohydrins under solvent-free conditions. J. Braz. Chem. Soc. 19 (8), 1595-1599.

4. Sajjadifar S., Mirshokraie S. A., Javaherneshan N., Louie O. (2012) SBSA as a New and efficient catalyst for the one-pot green synthesis of benzimidazole derivatives at room temperature. Am. $J$ Org. Chem., 2 (2), 1-6.

5. Dutta P., Sarma P., Borah R. (2013) P4VP-H2SO4-Catalyzed chemoselective protection of aldehydes to acylal along with deprotection reactions. Synth. Commun. , 43 (10), 1378-1386.

6. Borah K. J., Dutta P., Borah R. (2011) Synthesis, characterization and application of poly(4vinylpyridine)-supported Brønsted acid as reusable catalyst for acetylation reaction. Bull. Korean. Chem. Soc., 32 (1), 225-228.

7. Poupelin J. P., Saint-Ruf G., Foussard-Blanpin O., Narcisse G., Uchida-Ernouf G., Lacroix R.(1978 ) Synthesis and anti-inflammatory properties of bis-(2-hydroxy-1-naphthyl)-methane derivatives, I: polysubstituted and polycyclic derivatives. Eur. J. Med. Chem., 13, 67-71 and ref. cited therein.

8. Lacroix R., Arbeille B., Armaing C., Lacroix J., Reynouard F. (1985) Ultrastructural study of the in vitro mode of action of p-chlorophenyl bis-(2-hydroxynaphthyl) methane on trichomonas vaginalis. Ann. Pharm. Fr.,43 (5), 479-489 and references cited therein.

9. Banerjee A., Mukherjee A. K. (1981) Chemical aspects of santalin as a histological stain. Stain Technol. 56 (2), 83-85.

10. Bhowmik B. B., Ganguly P. (2005) Photophysics of xanthenes dyes in surfactant solution. Spectrochim Acta., Part A, 61 (9), 1997-2003.

11. Ion R. M. (1997) The photodynamic therapy of cancer-a photosensitization or a photocatalytic process. Prog. Catal, 2, 55-76 .

12. Ion R. M., Frackowiak D., Plannerm A., Wiktorowicz K. (1998) The incorporation of various porphyrins into blood cells measured via flow cytometry, absorption and emission spectroscopy. Acta. Biochim. Pol. 45 (3), 833-845.

13. Vries J. G. D., Lefort L. (2006) The combinatorial approach to asymmetric hydrogenation: phosphoramidite libraries, ruthenacycles, and artificial enzymes. Chem. Eur. J. 12 (18), 4722-4734.

14. Handique J. G., Barauh, J. B. (2002) Polyphenolic compounds: an overview. React. Funct. Polym. 52 (3), 163-188.

15. Olyaei A., Derikvand Z., Razeghi R., Sadeghpour M., Vaziri M. (2013) Zr-MCM-41 Nanoreactors: A highly efficient and reusable catalyst for the synthesis of 14-aryl-14H-dibenzo[a,j]xanthenes under solvent-free conditions. Open J. Org. Chem., 1 (2) 22-26.

16. Hunnur R. K., Sunilkumar. B., Kumar P. S., Srinivasulu N., Udupi R. H., Himabindu V. (2008) Silica sulfuric acid: A simple, efficient, and reusable heterogeneous catalyst for the one-pot synthesis of aryl-14h-dibenzo-[a,j] xanthenes under conventional heating and solvent-free conditions. Chem. Heterocycl. Compd. 44 (2), 143-147.

17. Bigdeli M. A., Heravi. M. M., Mahdavinia G. H. (2007) Silica supported perchloric acid ( $\mathrm{HClO}_{4}-$ $\mathrm{SiO}_{2}$ ): A mild, reusable and highly efficient heterogeneous catalyst for the synthesis of 14-aryl or alkyl-14-H-dibenzo [a,j] xanthenes. J. Mol.Catal. A: Chem., 275 (1-2), 25-29.

18. Heravi M. M., Bakhtiari K., Daroogheha Z. , Bamoharram FF. (2007) Facile heteropolyacidpromoted synthesis of 14-substituted-14-H-dibenzo[a,j]xanthene derivatives under solvent-free conditions. J. Mol. Catal. A: Chem. 273 (1-2), 99-101. 
19. Wang L-M., Sui Y-Y., Zhang L. (2008) Synthesis of 14-\{[(un)substituted phenyl] or alkyl $\}-14 \mathrm{H}-$ dibenzo[a,j]xanthenes Using $\mathrm{Yb}(\mathrm{OTf})_{3}$ as an efficient catalyst under solvent-free conditions. Chin. J. Chem. 26 (6), 1105-1108.

20. Sharifi A., Abaee M. S., Tavakkoli A., Mirzaei M., Zolfaghari A. (2008) Facile Montmorillonite K-10-supported synthesis of xanthene derivatives under microwave and thermal conditions. Synth. Commun. 38 (17), 2958-2966.

21. Madhav J. V., Reddy Y. T., Reddy P. N., Reddy M. N., Kuarm S., Crooks P. A., Rajitha B. (2009) Cellulose sulfuric acid: An efficient biodegradable and recyclable solid acid catalyst for the one-pot synthesis of aryl-14H-dibenzo[a.j]xanthenes under solvent-free conditions. J Mol.Catal. A: Chem. 304 (1-2), 85-87.

22. Ranjbar P. R., Abbasi A., Vafakish, B., Fischer A. (2007) 1-[(2-Hydroxy-1naphthyl)(phenyl)methyl]-2-naphthol ethanol solvate. Acta Cryst. E, 63 (5), o2093-o2094.

23. Alizadeh A., Khodaei M. M., Moradi K. H. (2010) Green and Diasteroselective Oxidative Cyclization of Bisnaphthols to Spirans. J. Iran.Chem. Soc., 7 (2), 351-358.

24. Ohishi T., Kojima T., Matsuoka T., Shiro M.,Kotsuki H. (2001) High-yielding TfOH-catalyzed condensation of phenols with aromatic aldehydes at high pressure. A model synthesis of the benzylidenebiphenol key skeleton of blepharismins. Tetra. Lett. 42 (13), 2493-2496.

25. Bamoniri A., Mirjalili B. B. F., Nazemian S. (2013) Microwave-assisted solvent-free synthesis of 14-aryl/alkyl-14H-dibenzo [a,j] xanthenes and tetrahydrobenzo[a]xanthen-11-ones catalyzed by nano silica phosphoric acid. Curr. Chem. Lett. 2 (1), 27-34.

26. Naeimi H., Nazifi Z. S. (2014) Environmentally benign and one-pot synthesis of 14-aryl-14Hdibenzo[a,j]xanthenes catalyzed by acyclic Brønsted acidic ionic liquid [H-NMP][HSO 4 ] under green conditions. C. R. Chimie. 17 (1), 41-48 and references cited therein.

27. Soleimani E., Khodaei M.M., Koshvandi A.T. K. (2011) The efficient synthesis of 14-alkyl or aryl 14Hdibenzo[a,j]xanthenes catalyzed by bismuth(III) chloride under solvent-free conditions. Chin. Chem. Lett, 22 (8), 927-930.

28. Kumar R., Nandi G.C., Verma R.K., Singh M.S. (2010) A facile approach for the synthesis of 14aryl- or alkyl-14H-dibenzo[a,j]xanthenes under solvent-free condition. Tetrahedron Lett., 51 (2), 442-445.

29.Maleki B., Gholizadeh M., Sepehr Z. (2011) 1,3,5-Trichloro-2,4,6-triazinetrion: a versatile heterocycle for the one-pot synthesis of 14-aryl- or alkyl -14H-dibenzo[a,j]xanthene, 1,8dioxooctahydroxanthene and 12-aryl-8,9,10,12-tetrahydrobenzo[a]xanthene-11-one derivatives under solvent-free conditions. Bull. Korean Chem. Soc. 32(5), 1697-1702.

30. Madhav J. V., Reddy Y. T., Reddy P.N., Reddy M. N., Kuarm S., Crooks P. A., Rajitha B. (2009) Cellulose sulfuric acid: an efficient biodegradable and recyclable solid acid catalyst for the one-pot synthesis of aryl-14H-dibenzo[a.j]xanthenes under solvent-free conditions. J. Mol. Cat. A: Chem., 304, 85-87. 